\title{
Development and Validation of the Hospital Outpatients' Information Needs Questionnaire (HOINQ)
}

This article was published in the following Dove Press journal: Patient Preference and Adherence

\author{
Mònica Andreu-March (D) \\ Margarita Aguas Compaired ${ }^{1,2}$ \\ Montserrat Pons Busom ${ }^{1,2}$ \\ Eduardo L Mariño (iD) \\ Pilar Modamio iD ' \\ 'Clinical Pharmacy and Pharmaceutical \\ Care Unit, Department of Pharmacy and \\ Pharmaceutical Technology and Physical \\ Chemistry, Faculty of Pharmacy and Food \\ Sciences, University of Barcelona, \\ Barcelona, 08028, Spain; ${ }^{2}$ Pharmacy \\ Service, University Hospital Sagrat Cor, \\ Barcelona, 08029, Spain
}

Correspondence: Pilar Modamio Clinical Pharmacy and Pharmaceutical Care Unit, Department of Pharmacy and Pharmaceutical Technology and Physical Chemistry, Faculty of Pharmacy and Food Sciences, University of Barcelona, Av. Joan XXIII, 27-3I, Barcelona, 08028, Spain $\mathrm{Tel} / \mathrm{Fax}+34934024544$

Email pmodamio@ub.edu
Purpose: The main objective was to develop and validate a "Hospital Outpatients' Information Needs Questionnaire" (HOINQ). Secondly, to identify patients' preferred sources of information. Finally, to establish differences depending on the disease, as well as between sociodemographic and clinical variables.

Patients and Methods: This is a transversal study based on a questionnaire. All adult hospital outpatients' who collected their medication at the Pharmacy Service were consecutively recruited, regardless of their diagnosis time, treatment or disease. The Spanish version of the internationally validated European Organization for Research and Treatment Cancer Quality of Life Questionnaire (EORTC QLQ-25) aimed at oncology patients was used as the starting point. In order to be applicable on new target population, it was crucial to make several changes and ensure that it complies with the validity, viability and reliability criteria. The questionnaire prepared for validation was then obtained by a literature review (face validity), submitting the EORTC QLQ-25 to an expert committee (content validity), by piloting (viability) and Cronbach's alpha statistical analysis (reliability). Once the questionnaire was completed, Cronbach's alpha of the final study (reliability) and factor analysis (construct validity) were performed. Then, pertinent modifications were applied to obtain the HOINQ.

Results: A total of 153 outpatients filled the questionnaire, which was widely accepted and required 5-10 min to complete. Cronbach's alpha coefficients met criteria $>0.7$. Three factors were established by factor analysis: aspects about the disease, pharmacological and no-pharmacological treatment and satisfaction and perception of the information received. Participants felt satisfied (41-52\%) with the information amount, quality and usefulness, although 1 out of 3 stated wanting to know more about the different information areas. Younger patients $(P$-value $<0.05)$ and those who had been attending the Pharmacy Service for a longer time span $(P$-value $<0.01)$ reported receiving more information. On a 0 to 7 scale, medical specialists (mean $=6.28, \mathrm{SD}$ $=1.38$ ) followed by the rest of health care professionals (mean $=4.23-4.63, \mathrm{SD}=$ 2.25-2.29) were selected as the preferred sources of information. HIV patients reported being more informed, while those with rheumatoid arthritis felt less informed ( $P$-value $<0.05)$.

Conclusion: The HOINQ was developed. It is a self-completed questionnaire, composed of three blocks: the 16-item information needs questionnaire, demographic and clinical variables, and patients' preferred sources of information. It is an easy tool to use and replicate, both for patients and professionals.

Keywords: information needs, outpatients, pharmacy service, questionnaire validation 


\section{Introduction}

Patient-centered care (PCC) involves empowering people to take charge of their own health. According to WHO, ${ }^{1}$

health systems oriented around the needs of people and communities are more effective, cost less, improve health literacy and patient engagement, and are better prepared to respond to health crises.

PCC is guided by different principles, including coordination between health professionals and levels of care, meeting the patients' needs after discharge and offering emotional support, as well as involving them in shared decision-making and providing the necessary information and education. ${ }^{2}$ Therefore, PCC represents a shift in the traditional roles of patients and their families, from a paternalistic model of passive "order-taker" to an active team member. In fact, increased patient participation is associated with better health outcomes, consequently health professionals are increasingly encouraged to involve patients. ${ }^{3}$

The prerequisite for this care is to provide effective and reliable information. Information is a collaborative process in which healthcare professionals and patients must work together. Health professionals should establish the information needs, goals, and patients' characteristics and health concerns. Furthermore, it is necessary to use comprehensive language and provide a comfortable environment, spending enough time with patients to ask questions and explore their information-seeking behavior. ${ }^{4}$ Finally, it is also important to re-evaluate their knowledge and satisfaction, in order to detect deficiencies and offer a personalized information care plan. $^{5}$ In this way, mechanisms can be provided to patients to manage their disease, improve adherence to treatments, decrease medication errors, and ultimately improve clinical outcomes. ${ }^{6}$

In recent years in Spain, there has been an increase in medicines dispensed from the hospital Pharmacy Service, a trend that will continue. ${ }^{7}$ This service cares for a large number of outpatients with a wide variety of diseases that need high-cost treatments and have special pharmacological features, such as complex dosage regiments and relevant side effects. Patients attend a first visit with the hospital pharmacist, and follow-up visits. The pharmacist is responsible for pharmacotherapeutic monitoring, as well as delivering information materials and patient education. From the Pharmacy Service, a privileged position is offered to carry out these interventions, because it is a meeting point for patients from different medical specialties and its proximity with the rest of the hospital's health professionals. ${ }^{8,9}$

Different studies assess the patients' information needs, as well as interviews and questionnaires. ${ }^{10-16}$ However, many are oriented to a single pathology and a significant variability exists among diseases in research and formulation of validated methods to assess, quantify, and compare information needs. For this reason, a pilot study to validate a questionnaire that analyzed the information needs of hospital outpatients, regardless of their pathology, time of diagnosis or treatment was carried out. As a result, a questionnaire prepared for validation was obtained. ${ }^{17}$

Thus, the main objective of the present study was to develop and validate a "Hospital Outpatients' Information Needs Questionnaire" (HOINQ). Secondly, to identify patients' preferred sources of information. Finally, to establish differences depending on the disease, as well as between sociodemographic and clinical variables. The tool obtained is intended to comprise the information received by patients on different areas related to their disease and treatment, and in the same way, to indicate what information they do and do not want to receive.

\section{Patients and Methods}

This research was approved by the medicinal Research Ethics Committee (REC) Idcsalud a Catalunya (2017/02FAR-HUSC). The study complies with the principles of the Declaration of Helsinki. Written informed consent was obtained from the patients prior to the study commencement. Patients were informed that participation was voluntary and confidential, and no data that could identify patients were collected.

\section{Study Design and Setting}

This is a transversal study based on a questionnaire and aimed at the outpatients of a 250-bed hospital in Barcelona (Spain). Outpatients were consecutively recruited when they attended the Pharmacy Service routinely to collect their medication. During the time of dispensing medicines, they were encouraged to participate, and after signing the informed consent, they received, completed and returned the printed questionnaire. Whenever necessary, the researcher could read the questions or resolve any doubts, without influencing the patient's response.

The inclusion criteria were adult ( $>18$ years old) outpatients who attend the Pharmacy Service regardless of their 
disease, time since diagnosis or treatment status. Those patients with severe physical or psychological problems, those who did not accept to participate or did not understand the questionnaire were excluded. Oncology patients were also excluded because a questionnaire specifically addressed to them that was used for the basis in our validation process, as mentioned below, was already. ${ }^{10,17}$

\section{Questionnaire Development}

The Spanish version of the internationally validated EORTC QLQ-25 questionnaire was used as the starting point. ${ }^{18,19}$ It is a 25 -item information module that was designed to evaluate the information received by the oncology patients, developed by the European Organization for Research and Treatment of Cancer (EORTC) Quality of Life Group. In the present study, the target population was expanded to outpatients with different diseases. For this reason, it was crucial to apply several changes to the EORTC QLQ-25 questionnaire and ensure that it complied with the validity, viability and reliability criteria. In this way, the questionnaire may be applicable to a new sample ${ }^{20}$ (Figure 1).

In order to comply with the face validity, a literature review was performed. ${ }^{11-14,21-31}$ Then, the different areas analyzed in terms of patient information were established. Content validity was conducted by an expert committee, consisting of six medical specialists who treat diseases that were most represented in the sample (two dermatologists, HIV, neurology, rheumatology and nephrology), two nurses and two pharmacists. After applying the suitable changes, the questionnaire prepared for piloting was obtained. During the piloting, the viability was analyzed applying the questionnaire to 30 patients, as well as reliability, by Cronbach's alpha analysis. Further modifications were made based on the preliminary results of the viability (observation criteria) and reliability (statistical criteria) to obtain the questionnaire prepared for validation. ${ }^{17}$

\section{Instrument}

The questionnaire prepared for validation is organized in three distinct blocks. The first block is composed of the questionnaire, consisting of 1-15 common items and 16-17 specific for neurology or rheumatology patients. The common items preserve the structure of the EORTC QLQ-25 questionnaire, in six areas, according to patients' perception of the information received about their disease (items 1-2), medical exams (items 3-4), treatment (items 5-7), other services (items 8-9), other areas (item 10) and satisfaction (items 11-15). All items (except satisfaction area) are supplemented by the question "Would you like more information?" aimed to identify needs of information. Thus, patients should respond how much information they had received on a Likert scale (1 - not at all, 2 - a little, 3 quite a bit, 4 - very much) and, simultaneously, answering for each item the yes/no extra-question. Items 12-13 have only a yes/no dichotomous response, depending on whether the patients would have liked to receive more or less information than that mentioned in the questionnaire.

The second block includes the sociodemographic and clinical variables. As for sociodemographic variables, gender, level of education (no schooling, primary school, secondary school, university studies) and age were asked. As for clinical variables, the disease, time since diagnosis and time since patient attends to Pharmacy Service.

The third block aims to analyze patients' preferred sources of information. The format response is a 0 to 7 scale ( 0 - no information, 4 - adequate information, 7 ideal information) depending on how much information patients would like to receive from each proposed source (general practitioners, medical specialists, nurses, pharmacists, friends/relatives, another person with the disease/ patient associations, pamphlets/leaflets, health magazines/ newspapers, internet, information campaigns).

\section{Sample Size}

A minimum of 150 patients were considered necessary (15 common items * 10 surveys). ${ }^{18}$ The $16-17$ specific items were also taken into account, so at least 9 out of 150 patients should come from rheumatology or neurology.

\section{Statistical Analysis}

The score of the questionnaire was standardized according to the principles previously established by the EORTC group. The internal consistency reliability was calculated in order to assess the relations between the elements of the questionnaire, both during the preliminary pilot study and the final validation process. The questionnaire was considered reliable with an index of $>0.7$ in Cronbach's alpha statistical analysis. ${ }^{18,20}$ Variables were standardized to allow comparability between the Likert-response items and the dichotomous. The construct validity was determined by a factor analysis, grouping the responses according to subscales. A principal component analysis (PCA) was previously performed, and Kaiser-Meyer-Olkin (KMO) sample adequacy measure index and Bartlett's sphericity test were used. KMO $\geq 0.8$ was considered acceptable and a significant result $(P$-value $<0.05)$ in the 


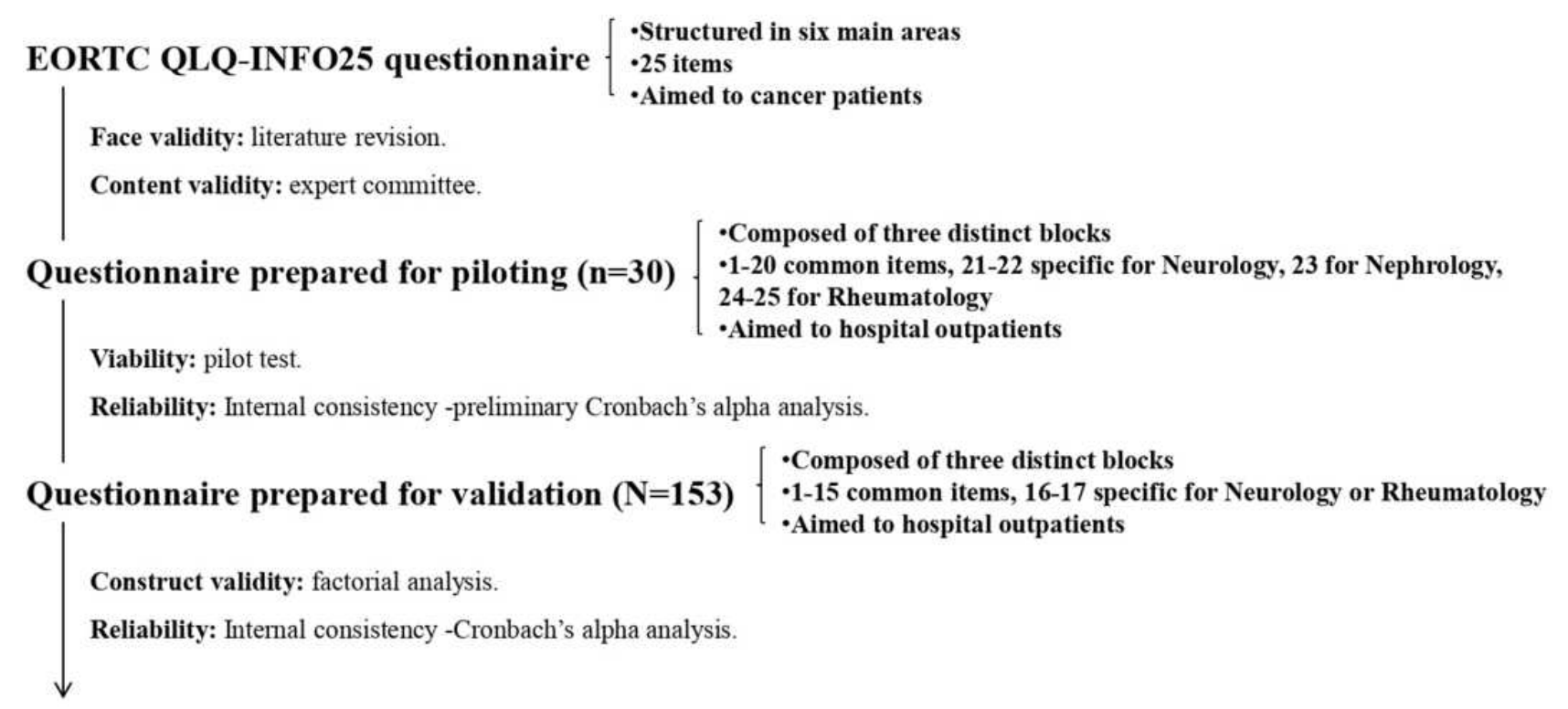

\section{Hospital Outpatients' Information Needs Questionnaire}

Figure I Scheme of the "Hospital Outpatients' Information Needs Questionnaire" (HOINQ) validation protocol.

Bartlett's test indicated that it was pertinent to perform the factor analysis. ${ }^{32}$ The number of factors was determined using the Kaiser criterion and the Varimax method for matrix rotation was selected.

To analyze the questionnaire' responses, a descriptive analysis assuming normality of distribution was performed using means and standard deviations (SD) for the quantitative variables, and the percentages for qualitative (nominal or ordinal). To compare the results according to the variables of interest, the mean value of the responses to each questionnaire item was also calculated. The $\chi^{2}$ test and Fischer's test were calculated for comparisons of qualitative variables. For a quantitative variable for two or more subgroups, the t-Student or the analysis of variance (ANOVA) were used, respectively. For multiple-comparison post-hoc correction Bonferroni procedure was selected. The Pearson correlation coefficients (Pearson's r) were used to relate two quantitative variables A $P$-value less than 0.05 was considered statistically significant. All data analysis was processed using SPSS version 24.0.

\section{Results}

\section{Validation Results and Psychometric Proprieties}

Regarding face validity, it was considered that the EORTC QLQ-25 questionnaire was appropriate to be used as the starting point of the validation process since the areas that compose it coincide with those previously established through literature review. This relation could be explained because oncology patients and the diseases included in the sample usually have common characteristics, such as chronicity and/or complex drug treatments that affect patients' quality of life.

To ensure content validity, different items were modified or deleted and the vocabulary was adapted to the new target population. The supplementary question "Would you like more information?" was also added next to the items. A new specific section was created aimed at neurology, nephrology and rheumatology patients. This section contained three items from the EORTC QLQ-INFO25 that the expert committee considered not applicable to all diseases, although important in certain specialties. The questionnaire prepared for piloting was obtained by renumbering the items and adding "Variables of interest" and "Preferred sources of information" blocks.

The questionnaire responds to the viability criteria because it was widely accepted by the patients and required $5-10 \mathrm{~min}$ to complete. Despite this, it was tedious especially for the elderly and those with multiple sclerosis, so it was considered pertinent to simplify it as much as possible. Also, the section addressed to nephrology patients was excluded by insufficient sample and neurology and rheumatology sections were unified in items $15-16$. 
Reliability was high since Cronbach's alpha coefficients met criteria $>0.7$ for all measurements, both preliminary and final. The internal consistency analysis of the pilot test $(n=30)$ obtained a Cronbach's alpha index of 0.878 for the common items. The specific items were excluded due to an insufficient sample. Secondly, the Cronbach's alpha index from the analysis of the definitive study ( $\mathrm{n}=153$ ) was 0.853 , including all common items, while the best statistical result was obtained by eliminating item 13 (0.868). The index was 0.894 when including the patients' responses who answered the common items plus the specific ones $(\mathrm{n}=38)$ and 0.897 by eliminating item 13 .

To evaluate construct validity, factor analysis was performed for all common items except item 13. In addition to improve Cronbach's alpha results, item 13 was excluded since the extraction of characteristics using PCA showed that it had the smallest anti-image value. The analysis was appropriate since the result of the KMO index was 0.874 and the Bartlett's test was significant. Three factors were established: factor 1 included the items $1-5$ and 8 (aspects about the disease), factor 2, the items 6-7 and 9-10 (about pharmacological and no-pharmacological treatment) and factor 3, items 11-12 and 14-15 (about satisfaction and perception of the information received). (Table 1)

Table I Rotated Component Matrix Containing Estimates of the Correlations Between Each of the Variables and Estimated Components. (Rotation Converged in 6 Interactions. Extraction Method: Principal Component Analysis. Rotation Method: Varimax with Kaiser Normalization)

\begin{tabular}{|l|l|l|l|}
\hline & \multicolumn{2}{l}{ Component } \\
\cline { 2 - 4 } & $\mathbf{I}$ & $\mathbf{2}$ & $\mathbf{3}$ \\
\hline Item 14 & 0.833 & 0.122 & 0.28 I \\
Item 15 & 0.830 & 0.103 & 0.212 \\
Item II & 0.786 & 0.148 & 0.267 \\
Item 12 & 0.652 & 0.213 & -.122 \\
Item 9 & -.007 & 0.742 & 0.05 I \\
Item 6 & 0.246 & 0.741 & 0.078 \\
Item 7 & 0.239 & 0.701 & 0.248 \\
Item 10 & 0.171 & 0.575 & 0.472 \\
Item 4 & 0.263 & 0.270 & 0.657 \\
Item 5 & -.245 & -.154 & 0.617 \\
Item 3 & 0.320 & 0.312 & 0.601 \\
Item 2 & 0.334 & 0.184 & 0.504 \\
Item I & 0.386 & 0.339 & 0.482 \\
Item 8 & 0.377 & 0.339 & 0.445 \\
\hline
\end{tabular}

\section{The "Hospital Outpatients' Information Needs Questionnaire"}

Item 13 was removed and item 8 was reordered based on validation results. After that, all items were renumbered. The information needs validated questionnaire was then obtained: a 16-item self-completion questionnaire that consists of 1-14 common items aimed at the hospital outpatients and 15-16 specific for neurology or rheumatology. The items were organized according to the three information areas previously determined by factor analysis. The HOINQ maintained the structure in three blocks: the 16item information needs validated questionnaire (block 1), demographic and clinical variables (block 2) and patients' preferred sources of information (block 3) (Table 2).

\section{Questionnaire Responses}

A total of 153 outpatients filled the questionnaire, from January to June 2018. Table 3 shows demographic and clinical variables. The $56 \%$ were men, $41 \%$ had university studies and patients' age varied between 18 and 97 years old (median 53 years-old). The most represented disease was psoriasis (34\% of patients). In other diseases category, highlighted a group of 9 patients with hepatitis $(6 \%)$. The registered disease corresponds to patients' diagnosis for each dispensed treatment. It should be added that no patient collected more than one medication at the same time within the study period. An average of 12 years elapsed since patients' diagnosis and of 5 years since attending the Pharmacy Service, so it took about 8 years since they attended the Pharmacy Service for the first time after being diagnosed. Table 4 contains the patients' responses to the items that compose block 1 of the questionnaire prepared for validation, structured according to the six information areas (1-15 common items). The 16-17 specific items for Neurology/Rheumatology services were also included in Table 4. Each Likert-type response was subdivided into two options, depending on whether the patients stated (or not) that they wanted to receive more information. Patients reported receiving "quite a bit" (37-48\%) or "very much" (40-56\%) information about the different areas covered in the questionnaire, but this trend was not so defined in items 6,9 and 10. It highlighted that $45 \%$ were not informed about the possibility of receiving professional psychological support (item 9) but it should be taken into account that $77 \%$ of the respondents to item 9 would not like to receive more information. Against, a percentage of $23-34 \%$ would like to know more about the different 
Table 2 Definitive Structure of the "Hospital Outpatients' Information Needs Questionnaire” (HOINQ), After Applying Appropriate Modifications During the Validation Process

\begin{tabular}{|c|c|}
\hline \multicolumn{2}{|c|}{ Block I: The Validated Questionnaire } \\
\hline $\begin{array}{l}\text { Item I-6: Information about the } \\
\text { disease }\end{array}$ & $\begin{array}{l}\text { [1] Disease diagnosis } \\
\text { [2] If the disease is under control } \\
\text { [3] Medical tests purpose } \\
\text { [4] Medical tests results } \\
\text { [5] Treatment expected benefits } \\
\text { [6] Management of disease in daily } \\
\text { activities }\end{array}$ \\
\hline $\begin{array}{l}\text { Item 7-10: Information about } \\
\text { pharmacological and no- } \\
\text { pharmacological treatment }\end{array}$ & $\begin{array}{l}\text { [7] Treatment potential side- } \\
\text { effects } \\
\text { [8] Treatment effects on quality of } \\
\text { life } \\
\text { [9] The possibility of receiving } \\
\text { professional psychological support } \\
\text { [10] Things to do to get well }\end{array}$ \\
\hline $\begin{array}{l}\text { Item II-I4: Information about } \\
\text { satisfaction and perception of } \\
\text { the information received }\end{array}$ & $\begin{array}{l}\text { [II] Information amount } \\
\text { [12] Patient would like to receive } \\
\text { more information than mentioned } \\
\text { above } \\
\text { [13] Information quality } \\
\text { [14] Information usefulness }\end{array}$ \\
\hline $\begin{array}{l}\text { Item 15-16: Information specific } \\
\text { for Neurology/Rheumatology } \\
\text { services }\end{array}$ & $\begin{array}{l}\text { [15] Medical tests procedures } \\
\text { [16] Rehabilitation services }\end{array}$ \\
\hline \multicolumn{2}{|l|}{ Block 2: Variables of Interest } \\
\hline Demographical & Gender, level of education, age \\
\hline Clinical & $\begin{array}{l}\text { Disease, time since diagnosis, time } \\
\text { since patient attends the } \\
\text { Pharmacy Service }\end{array}$ \\
\hline \multicolumn{2}{|c|}{ Block 3: Preferred Sources of Information } \\
\hline Proposed sources & $\begin{array}{l}\text { General practitioners, medical } \\
\text { specialists, nurses, pharmacists, } \\
\text { friends/relatives, another person } \\
\text { with the disease/patient } \\
\text { associations, pamphlets/leaflets, } \\
\text { health magazines/newspapers, } \\
\text { internet, information campaigns }\end{array}$ \\
\hline
\end{tabular}

questionnaire areas, especially potential treatment sideeffects (34\%). As topics not mentioned in the questionnaire, participants reported wanting to know more about the disease features, its transmission and medical advances. Patients were satisfied (41-52\%) with the information amount, quality and usefulness. The specific items 16-17
Table 3 Demographic and Clinical Variables

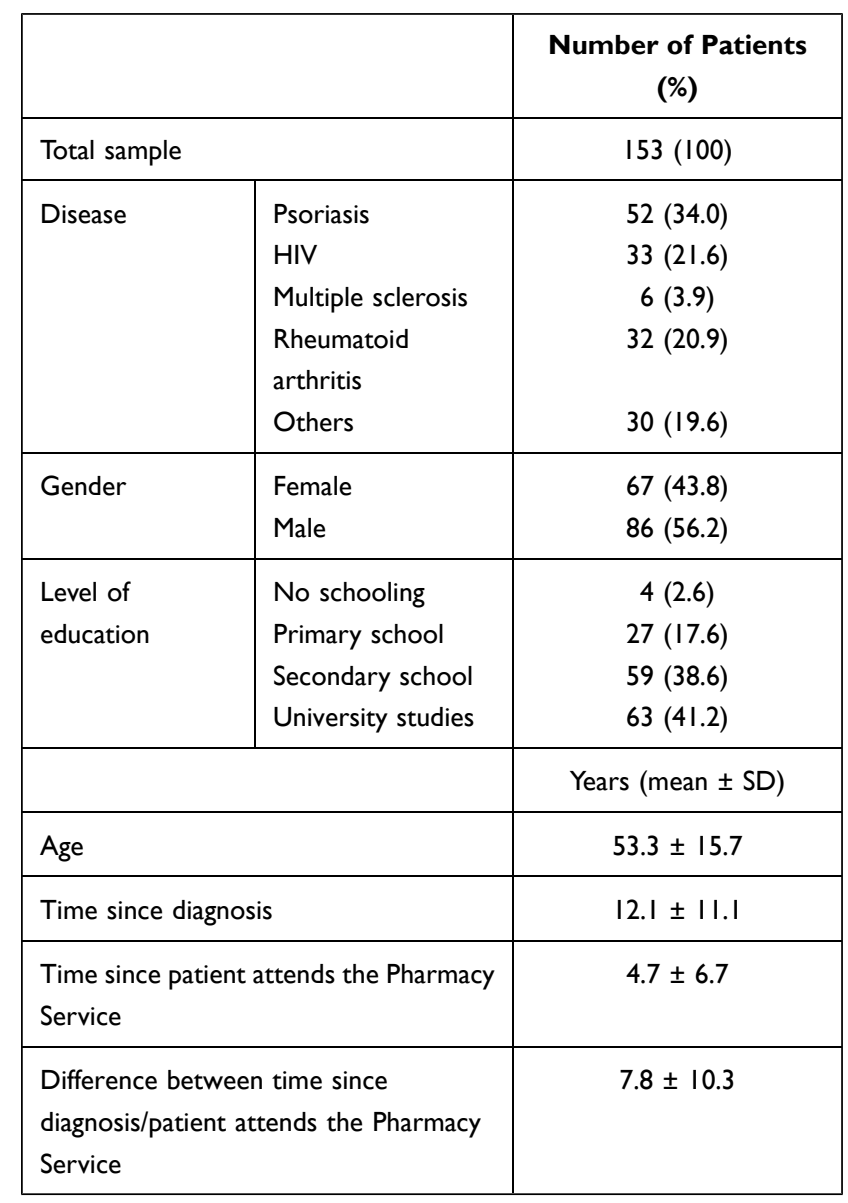

Abbreviation: HIV, human immunodeficiency virus.

were answered by 38 patients, 32 from rheumatology service and 6 from neurology.

Regarding the analysis for the other variables, older patients reported having received less information according to the mean value of all questionnaire responses (Pearson's $r=-0.164, P$-value $<0.05$ ), while the time since patient attends to the Pharmacy Service was related to a higher mean value (Pearson's $r=0.220$, $P$-value $<0.01)$. No relevant differences were established between responses and gender or level of education. The responses depending on patients' disease are represented in Figure 2. Statistically significant differences between diseases were found in all information areas $(\mathrm{F}=6.003$, $P$-value $<0.05$ ). Rheumatoid arthritis patients were who receive less information, especially about pharmacological and no-pharmacological treatment (mean $=2.32$, SD $=0.65)$. On the other hand, patients with HIV reported receiving more information, highlighting the best value in disease information area $($ mean $=3.55, \mathrm{SD}=0.47)$. 
Table 4 Patients' Responses to the Questionnaire Prepared for Validation

\begin{tabular}{|c|c|c|c|c|c|c|}
\hline & \multirow{2}{*}{$\begin{array}{l}\text { Would Patients } \\
\text { Like More } \\
\text { Information? }\end{array}$} & \multicolumn{4}{|c|}{ How Much Information Patients Had Received? N (\%) } & \multirow[t]{2}{*}{ Total N (\% } \\
\hline & & Not at All & A little & Quite a Bit & Very Much & \\
\hline \multicolumn{7}{|c|}{ Items I-2: Information about the disease } \\
\hline \multirow[t]{2}{*}{ [I] Disease diagnosis } & Yes & $2(1.3)$ & $9(5.9)$ & $19(12.4)$ & $14(9.2)$ & $44(28.8)$ \\
\hline & No & I (0.7) & $4(2.6)$ & $45(29.4)$ & $59(38,6)$ & $109(7 \mid .2)$ \\
\hline \multirow{2}{*}{$\begin{array}{l}\text { [2] If the disease is under } \\
\text { control }\end{array}$} & Yes & $\mathrm{I}(0.7)$ & $10(6.5)$ & $21(13.7)$ & II (7.2) & $43(28.1)$ \\
\hline & No & $2(1.3)$ & $3(2.0)$ & $39(25.5)$ & $66(43.1)$ & 110 (7I.9) \\
\hline \multicolumn{7}{|c|}{ Items 3-4: Information about medical tests } \\
\hline \multirow[t]{2}{*}{ [3] Medical tests purpose } & Yes & $4(2.6)$ & $4(2.6)$ & $27(17.6)$ & $4(2.6)$ & $39(25.5)$ \\
\hline & No & I (0.7) & $4(2.6)$ & $46(30.1)$ & $63(4 I .2)$ & II4 (74.5) \\
\hline \multirow[t]{2}{*}{ [4] Medical tests results } & Yes & $2(1.3)$ & $5(3.3)$ & $27(17.6)$ & $5(3.3)$ & $39(25.5)$ \\
\hline & No & I $(0.70)$ & $\mathrm{I}(0.7)$ & $46(30.1)$ & $66(43.1)$ & II 4 (74.5) \\
\hline \multicolumn{7}{|c|}{ Items 5-7: Information about treatment } \\
\hline \multirow{2}{*}{$\begin{array}{l}\text { [5] Treatment expected } \\
\text { benefits }\end{array}$} & Yes & $\mathrm{I}(0.7)$ & $5(3.3)$ & $19(12.4)$ & $12(7.8)$ & $37(24.2)$ \\
\hline & No & $0(0)$ & $5(3.3)$ & $37(24.2)$ & $74(48.4)$ & $116(75.8)$ \\
\hline \multirow{2}{*}{$\begin{array}{l}\text { [6] Treatment potential side- } \\
\text { effects }\end{array}$} & Yes & $8(5.2)$ & $14(9.2)$ & $22(14.4)$ & $8(5.2)$ & $52(34.0)$ \\
\hline & No & $7(4.6)$ & $22(14.4)$ & $32(20.9)$ & $40(26.1)$ & $101(66.0)$ \\
\hline \multirow{2}{*}{$\begin{array}{l}\text { [7] Treatment effects on } \\
\text { quality of life }\end{array}$} & Yes & $5(3.3)$ & $7(4.6)$ & $22(14.4)$ & $10(6.5)$ & $44(28.8)$ \\
\hline & No & $7(4.6)$ & $10(6.5)$ & $35(22.9)$ & $57(37.3)$ & 109 (7I.2) \\
\hline \multicolumn{7}{|c|}{ Items 8-9: Information about other services } \\
\hline \multirow{2}{*}{$\begin{array}{l}\text { [8] Management of the disease } \\
\text { in daily activities }\end{array}$} & Yes & $6(3.9)$ & $6(3.9)$ & $16(10.5)$ & $7(4.6)$ & $35(22.9)$ \\
\hline & No & $6(3.9)$ & $12(7.8)$ & $46(30.1)$ & $54(35.3)$ & $118(77.1)$ \\
\hline \multirow{2}{*}{$\begin{array}{l}\text { [9] The possibility of receiving } \\
\text { professional psychological } \\
\text { support }\end{array}$} & Yes & $21(13.7)$ & $9(5.9)$ & $3(2.0)$ & $3(2.0)$ & $36(23.5)$ \\
\hline & No & $48(31.4)$ & $22(14.4)$ & $21(13.7)$ & $26(17.0)$ & $117(76.5)$ \\
\hline \multicolumn{7}{|c|}{ Item 10: Information about other areas } \\
\hline \multirow[t]{2}{*}{ [10] Things to do to get well } & Yes & $8(5.2)$ & $2 \mid(13.7)$ & $13(8.5)$ & $4(2.6)$ & $46(30.1)$ \\
\hline & No & $10(6.5)$ & $2 \mid(13.7)$ & $36(23.5)$ & $40(26.1)$ & $107(69.9)$ \\
\hline \multicolumn{7}{|c|}{ Items II-I 5: Perception of satisfaction of the information received } \\
\hline & & Not at all & A little & Quite a bit & Very much & \\
\hline \multirow[t]{2}{*}{ [II] Information amount } & & $0(0)$ & $12(7.8)$ & $78(51.0)$ & $63(4 I .2)$ & \\
\hline & \multicolumn{3}{|c|}{ Yes } & \multicolumn{3}{|c|}{ No } \\
\hline $\begin{array}{l}\text { [12] Patient would like to } \\
\text { receive more information than } \\
\text { mentioned }\end{array}$ & \multicolumn{3}{|c|}{$59(38.6)$} & \multicolumn{3}{|c|}{94 (61.4) } \\
\hline
\end{tabular}


Table 4 (Continued).

\begin{tabular}{|c|c|c|c|c|c|c|}
\hline & \multirow{2}{*}{$\begin{array}{l}\text { Would Patients } \\
\text { Like More } \\
\text { Information? }\end{array}$} & \multicolumn{4}{|c|}{ How Much Information Patients Had Received? N (\%) } & \multirow[t]{2}{*}{ Total N (\%) } \\
\hline & & Not at All & A little & Quite a Bit & Very Much & \\
\hline \multirow{2}{*}{$\begin{array}{l}\text { [13] Patient would like to } \\
\text { receive less information than } \\
\text { mentioned }\end{array}$} & \multicolumn{3}{|c|}{$2(1.3)$} & \multicolumn{3}{|c|}{ I5I (98.7) } \\
\hline & & Not at all & A little & Quite a bit & Very much & \\
\hline [14] Information quality & & I (0.7) & $9(5.9)$ & $80(52.3)$ & $63(41.2)$ & \\
\hline [15] Information usefulness & & $0(0)$ & $9(5.9)$ & $71(46.4)$ & $73(47.7)$ & \\
\hline \multicolumn{7}{|c|}{ Items 16-17: Information specific for Neurology/Rheumatology services } \\
\hline \multirow[t]{2}{*}{ [16] Medical tests procedures } & Yes & I (2.6) & $7(18.4)$ & $4(10.5)$ & $0(0)$ & $12(31.6)$ \\
\hline & No & $0(0)$ & $4(10.5)$ & $13(34.2)$ & $9(23.7)$ & $26(68.4)$ \\
\hline \multirow[t]{2}{*}{ [17] Rehabilitation services } & Yes & $10(26.3)$ & $5(13.2)$ & I (2.6) & I (2.6) & I7 (44.7) \\
\hline & No & $9(23.7)$ & $3(7.9)$ & $4(10.5)$ & $5(13.2)$ & $21(55.3)$ \\
\hline
\end{tabular}

Patients preferred to be informed by the medical specialists (mean $=6.28, \mathrm{SD}=1.38)$ and the rest of health professionals $($ mean $=4.23-4.63, \mathrm{SD}=2.25-2.29)$. The patients' assessment from all other sources of information did not reach the average (mean $=3.85, \mathrm{SD}=1.74$ ) and friends and relatives were ranked as the worst qualified source $($ mean $=2.27, \mathrm{SD}=2.29)$. (Figure 3 )

\section{Discussion}

The HOINQ complies with the high validity, reliability and viability requirements. These positive results were expected, since an internationally validated questionnaire was used as the starting point of the development process. However, it was indispensable to be analyzed by an expert committee to adapt it to a new sample. Also, it was considered necessary to simplify the questionnaire in order to obtain a tool easy to be used and interpreted, for both patients and professionals. Item 13 (patient would like to receive less information than mentioned above) was removed then for statistical reasons by increasing reliability and observational, as only two people stated that they wished they had received less information. In addition, it can be considered dispensable because the question is already included in a diversified way after answering "Would you like more information?" for each Likert-response item. Adding this extra question during the validity process was crucial to fulfill the study objective and to analyze the patients' information needs, and not only the amount of information previously received. For example, responders only received "a little" information about item 9 and we could consider it as a negative fact, but that area was no longer interesting for them. The opposite can also happen, so asking the extra question allows avoiding false negatives and positives, and thus correctly interpret the responses. As a result, it is possible to truly adapt the information according to patient concerns. On the other hand, the factor analysis allowed guaranteeing that the results could be considered as a measure of the studied phenomenon. Grouping the responses based on underlying factors also allowed reordering and simplifying the questionnaire structure. According to these results, it should be noted that item 5 (treatment expected benefits) is located in factor 1, the disease information area. This may reflect that patients related treatment expected benefits to a potential improvement in their disease. Finally, item 5 was not removed because it would worsen Cronbach's alpha value as well as its anti-image value.

According to the descriptive findings, the heterogeneity of the sample (Table 3) added significance to the results. It agrees with literature that younger patients have more information needs and concerns, and also feel more informed. ${ }^{15,18,33,34}$ Therefore, it becomes important for health professionals to spend more time instructing the elderly, due to their age-specific difficulties in understanding. ${ }^{35}$ As mentioned above, no significant 


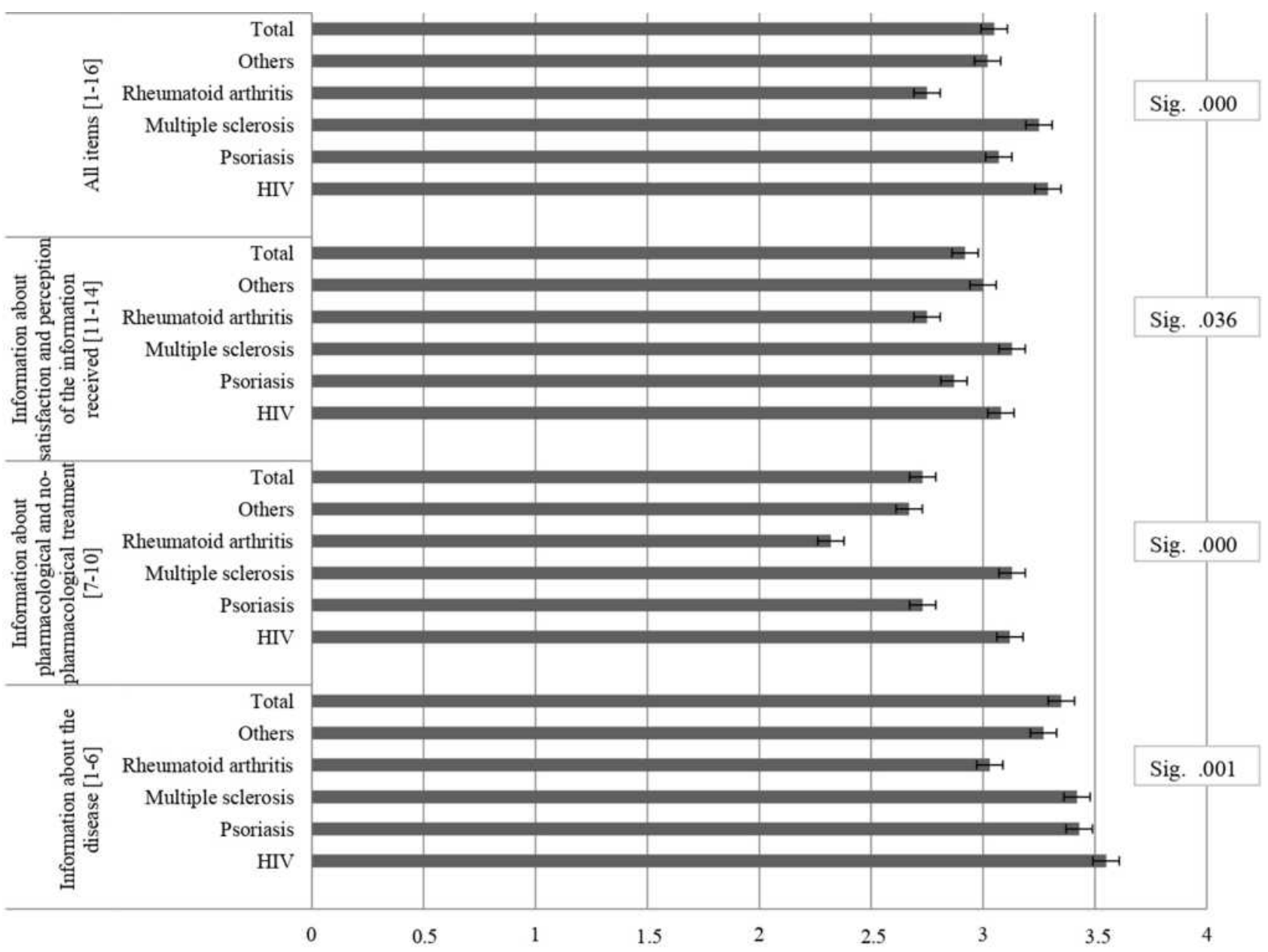

Figure 2 Responses' mean values to all questionnaire items and also grouped according to the three definitive information areas, differentiating patients' diseases.

differences were found in this study between gender or educational level. Even so, the literature describes that a high level of studies is related to a better level of information. ${ }^{11,30,36}$ This relation has probably not been established in this study because the hospital is located in an area considered to be of medium-high educational level, as also it was observed in the demographic variables results. ${ }^{37}$ Additionally, it is important to note that it had elapsed a long period of time since their diagnosis and their visits to the Pharmacy Service. This time span occurs because patients suffer chronic diseases and hospital treatments are not usually of first choice.

Regarding questionnaire responses, patients reported being satisfied and well informed. These results agreed with those obtained during the pilot study. ${ }^{17}$ However, it is necessary to emphasize that 1 out of 3 patients stated that they wanted to know more, similarly distributed in the different information areas. The responses of the specific items cannot be extrapolated due to insufficient sample.
Moreover, different results were detected depending on disease. HIV patients stated being more informed, probably because they have been visiting the Pharmacy Service for the longest time, since their medication is dispensed from the hospital at all stages of their diseases. This result was expected due to the relation established between the time frame attending the Pharmacy Service and greater reported information amount. Conversely, rheumatoid arthritis patients felt less informed. It has already been observed in other studies a lack of knowledge and very high need for information in outpatients with rheumatoid arthritis. ${ }^{15,33}$ Detecting these differences is crucial to customize the interventions according to each group of patients, such as adapting the information delivery materials or establishing the visits frequency. ${ }^{33,35}$ In concordance with previous research, health professionals are situated as the preferred source of information. ${ }^{11,12,15}$ In younger populations, a greater use of Internet was observed for health-related information search. ${ }^{5,15,36}$ 


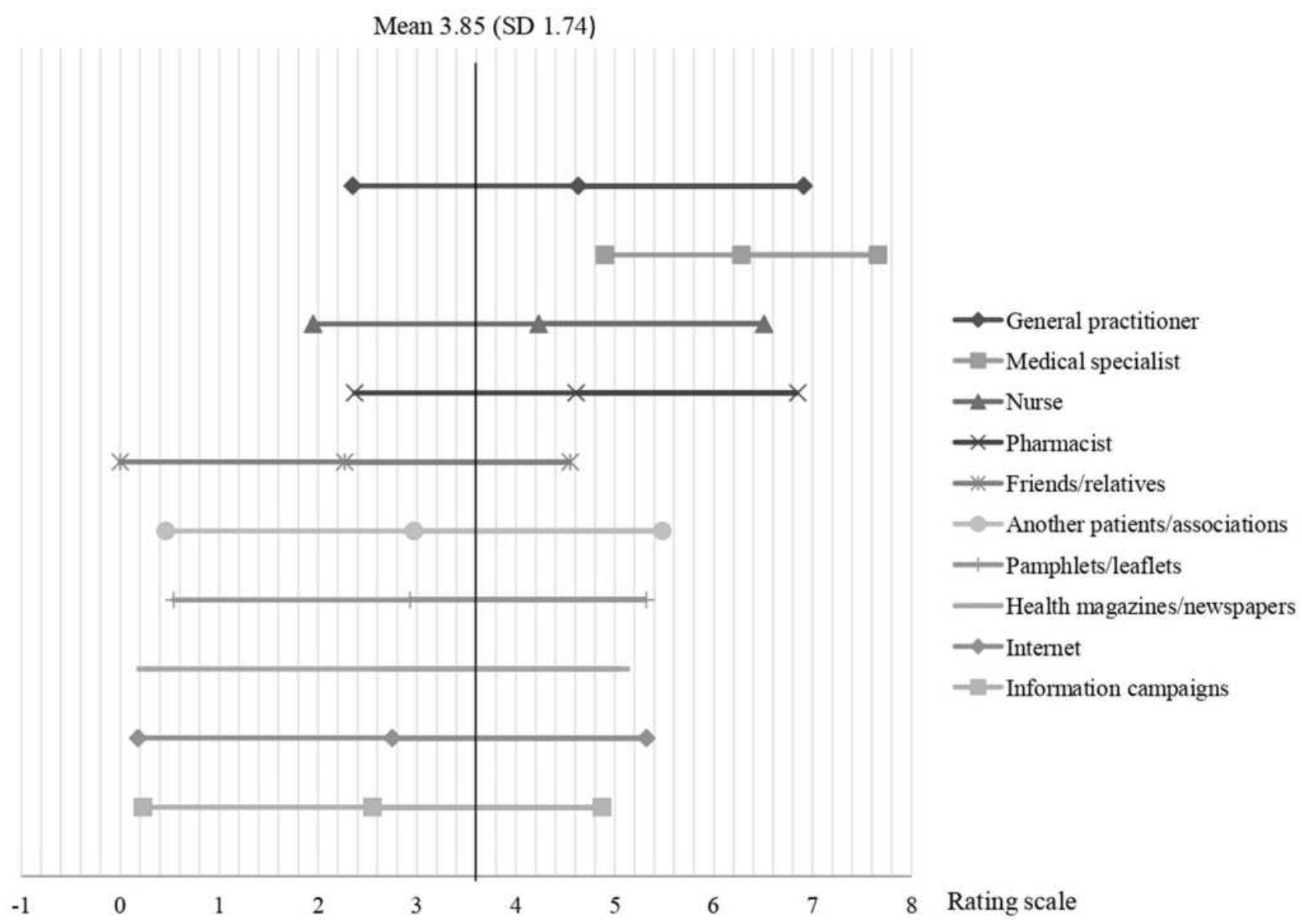

Figure 3 Patients' preferred sources of information.

A self-completed questionnaire is an economic system of collecting information, easy to replicate in daily practice as well as in future studies. ${ }^{38}$ Furthermore, being completed from the Pharmacy Service, at the time of collecting the medication, allowed the presence of a health professional to solve potential doubts without influencing the patients' responses. ${ }^{35}$ In fact, it was observed that the patients to whom the questionnaire was administered asked more questions than those who only went to collect their medication. Interestingly, the questions were not about the questionnaire itself, but to patients' own doubts. This represents an opportunity for pharmacists, who work in a multidisciplinary health care team, can guide and improve patient empowerment. Finally, the questionnaire became a practical and efficient validated tool, since it was widely accepted, required little time and could be used in outpatients with various diseases, regardless of their treatment or diagnosis time.

\section{Limitations}

Although the necessary sample size was established for the development and validation of the questionnaire, it would be interesting to replicate the study to other hospitals. By doing this, different realities could be analyzed and, consequently, the information could be better adapted to patients. It would also allow improving the questionnaire's properties, especially the factor analysis, as its stability increases with the sample size. $^{32}$

\section{Conclusions}

The HOINQ was developed. It is a self-completed questionnaire, aimed at the outpatients who collect their medication at the Pharmacy Service from the hospital. Its structure is composed of three blocks: the 16-item information needs questionnaire, demographic and clinical variables, and patients' preferred sources of information. It complies with the validity, viability and 
reliability criteria and thus becomes an easy tool to use and replicate, both for patients and professionals.

The outpatients reported being satisfied and well informed, although 1 out of 3 stated wanting to know more about the different information areas covered in the questionnaire. Also, participants selected the medical specialists, and secondly, the rest of health care professionals, as their preferred sources of information.

Younger patients, as well as those who had been attending the Pharmacy Service for a longer time span, reported receiving more information. Significant differences were also established between the responses and the different studied diseases. HIV patients reported being more informed, while those with rheumatoid arthritis felt less informed.

\section{Data Sharing Statement}

The dataset used is available from the corresponding author upon request.

\section{Acknowledgments}

The authors acknowledge the patients and the professionals of Pharmacy Service of the University Hospital Sagrat Cor in Barcelona, Spain, for their cooperation during data collection.

\section{Author Contributions}

MAC and PM were involved in the conception and design of the study, protocol development, interpretation of the data, and drafting the manuscript. MA-M was involved in the design of the study, protocol development, data collection, data entry, interpretation of the data, and drafting the manuscript. MP and ELM were involved in the design and review of protocol development, interpretation of the data, and review of the manuscript. All authors read and approved the final manuscript. All authors contributed to data analysis, drafting or revising the article, have agreed on the journal to which the article will be submitted, gave final approval of the version to be published, and agree to be accountable for all aspects of the work.

\section{Funding}

There is no funding to report.

\section{Disclosure}

Margarita Aguas Compaired was excluded from the review and approval of this research by the ethical committee. The authors report no conflicts of interest for this work.

\section{References}

1. World Health Oraganization. What are integrated people-centred health services? Available from: https://www.who.int/servicedelivery safety/areas/people-centred-care/ipchs-what/en/. Accessed June 9, 2020.

2. Rapid T, Service R, Cadth W. Patient- and Family-Centered Care Initiatives in Acute Care Settings: A Review of the Clinical Evidence, Safety and Guidelines. Cadth; 2015. Available from: https://www. ncbi.nlm.nih.gov/books/NBK350000/. Accessed July 14, 2020.

3. Molina F, Castaño E, Massó J. Educational experience with the expert patient. Rev Clín Med Fam. 2008;2(4):178-180.

4. Anonymous. What is patient-centered care? NEJM Catal Innov Care Deliv. 2017;3(1).

5. Clarke MA, Moore JL, Steege LM, et al. Health information needs, sources, and barriers of primary care patients to achieve patient-centered care: a literature review. Health Informatics J. 2016;22(4):992-1016. doi:10.1177/1460458215602939

6. Epstein RM, Fiscella K, Lesser CS, Stange KC. Why the nation needs a policy push on patient-centered health care. Health Aff. 2010;29(8):1489-1495. doi:10.1377/hlthaff.2009.0888

7. Godman B, Bucsics A, Vella Bonanno P, et al. Barriers for access to new medicines: searching for the balance between rising costs and limited budgets. Front Public Health. 2018;6:328.

8. Valdivieso JG, Navarro MG, Ribes JJM, et al. [Multicenter study of patients' satisfaction in outpatient dispensing]. Aten Farm. 2012;14 (3):152-159. Spanish.

9. Díaz Gómez E, Lázaro López A, Horta Hernández A. Analysis of pharmaceutical intervention in outpatients pharmacy department. Farm Hosp. 2013;37(4):295-299. doi:10.7399/FH.2013.37.4.588

10. Arraras JI, Greimel E, Chie WC, et al. Information disclosure to cancer patients: EORTC QLQ-INFO25 questionnaire. Expert Rev Pharmacoecon Outcomes Res. 2011;11(3):281-286. doi:10.1586/ erp.11.29

11. Mekuria AB, Erku DA, Belachew SA. Preferred information sources and needs of cancer patients on disease symptoms and management: a cross-sectional study. Patient Prefer Adherence. 2016;10:1991-1997. doi:10.2147/PPA.S116463

12. Matti AI, Mccarl H, Klaer P, Keane MC, Chen CS. Multiple sclerosis: patients' information sources and needs on disease symptoms and management. Patient Prefer Adherence. 2010;4:157-161. doi:10.2147/PPA.S10824

13. Altobelli E, Maccarone M, Petrocelli R, et al. Analysis of health care and actual needs of patients with psoriasis: a survey on the Italian population. BMC Public Health. 2007;7:59. doi:10.1186/1471-2458-7-59

14. Leydon GM, Boulton M, Moynihan C, et al. Information in practice cancer patients' information needs and information seeking behaviour: in depth interview study. BMJ. 2000;320(7239):909-913. doi:10.1136/bmj.320.7239.909

15. Neame R, Hammond A, Deighton C. Need for information and for involvement in decision making among patients with rheumatoid arthritis: a questionnaire survey. Arthritis Rheum. 2005;53 (2):249-255. doi:10.1002/art.21071

16. Suhonen R, Nenonen H, Laukka A, Välimäki M. Patients' informational needs and information received do not correspond in hospital. $J \quad$ Clin Nurs. 2005;14(10):1167-1176. doi:10.1111/j.13652702.2005.01233.x

17. Andreu-March M, Aguas M, Piñero-López MÁ, Pons M, Mariño EL, Modamio P. Analysis of hospital outpatients' information needs: a pilot study of a questionnaire validation. Lat Am J Pharm. 2019;38(5):866-873.

18. Arraras JI, Greimel E, Sezer O, et al. An international validation study of the EORTC QLQ-INFO25 questionnaire: an instrument to assess the information given to cancer patients. Eur $J$ Cancer. 2010;46(15):2726-2738. doi:10.1016/j.ejca.2010.06.118 
19. Arrarás JI, Manterola A, Hernández B, et al. The EORTC information questionnaire, EORTC QLQ-INFO25: validation study for Spanish patients. Clin Transl Oncol. 2011;13(6):401-410. doi:10.1007/ s12094-011-0674-1

20. García de Yébenes Prous MJ, Rodríguez Salvanés F, Carmona Ortells L. Validation of questionnaires. Reumatol Clin. 2009;5 (4):171-177. doi:10.1016/j.reuma.2008.09.007

21. Shea-Budgell MA, Kostaras X, Myhill KP, Hagen NA. Information needs and sources of information for patients during cancer follow-up. Curr Oncol. 2014;21(4):165-173. doi:10.3747/co.21.1932

22. Hepworth M, Harrison J, James N. A discussion of the information needs of people with multiple sclerosis (MS) and the implications for information provision based on a national UK survey of people with MS. Aslib Proc. 2003;55(5/6):290-303. doi:10.1108/ 00012530310498860

23. Heesen C, Rgen Kasper J, Segal J, Kö Pke S, Mü Hlhauser I. Decisional role preferences, risk knowledge and information interests in patients with multiple sclerosis. Mult Scler. 2004;10:1-8. doi:10.1191/1352458504ms1112oa

24. Nureña CR. Information and uncertainty in lives with HIV: ethnographic study with people with HIV in Lima, Perú. Inf Cult y Soc. 2011;25:87-116.

25. Ankem K. Types of information needs among cancer patients: a systematic review. Libres. 2005;15(2):1-25.

26. Schook RM, Linssen C, Festen J, et al. Website visitors asking questions online to lung cancer specialists: what do they want to know? Interact J Med Res. 2013;2(2):e15. doi:10.2196/ijmr.1749

27. Da Costa Pereira AC Assessing the Information Given to Cancer Patients Attending Day Hospital in a Comprehensive Cancer Centre master's dissertation. Universidade do Porto; 2011. Available from: https://pdfs.semanticscholar.org/11d0/ a7835e9ef8c7c9c83bdc1b6da98414abfdb5.pdf?.ga=2.239610371. 1268309093.1599258682-457483930.1599258682. Accessed July 14, 2020.

28. Armstrong A, Jarvis S, Boehncke W-H, et al. Patient perceptions of clear/almost clear skin in moderate-to-severe plaque psoriasis: results of the clear about psoriasis worldwide survey. J Eur Acad Dermatol Venereol. 2018;32(12):2200-2207. doi:10.1111/jdv.15065
29. Dubertret L, Mrowietz U, Ranki A, et al. European patient perspectives on the impact of psoriasis: the EUROPSO patient membership survey. $B r J$ Dermatol. 2006;155(4):729-736. doi:10.1111/j.13652133.2006.07405.x

30. Carrón Sánchez J, Arza Porras J. Multiple sclerosis: needs analysis and quality of life of affected people and their environment. Rev Esp Discapac. 2013;1(2):59-75.

31. De Las Cuevas C, de Leon J. Development and validation of the patient's health belief questionnaire on psychiatric treatment. Patient Prefer Adherence. 2019;13:527-536. doi:10.2147/PPA.S201144

32. Lacave Rodero C, Molina Diaz AI, Fernández Guerrero M, Redondo Duque MÁ. [Analysis of the reliability and validity of a teaching questionnaire]. ReVisión. 2016;9(1). Spanish.

33. Meesters J, de Boer I, van den Berg M, Fiocco M, Vliet Vlieland T. Unmet information needs about the delivery of rheumatology health care services: a survey among patients with rheumatoid arthritis. Patient Educ Couns. 2011;85(2):299-303. doi:10.1016/j. pec.2010.10.004

34. Kjeken I, Dagfinrud H, Mowinckel P, Uhlig T, Kvien TK, Finset A. Rheumatology care: involvement in medical decisions, received information, satisfaction with care, and unmet health care needs in patients with rheumatoid arthritis and ankylosing spondylitis. Arthritis Rheum. 2006;55(3):394-401. doi:10.1002/art.21985

35. Sanchez Ulayar A, Gallardo Lopez S, Pons Llobet N, Murgadella Sancho A, Campins Bernadàs L, Merino Mendez R. Pharmaceutical intervention upon hospital discharge to strengthen understanding and adherence to pharmacological treatment. Farm Hosp. 2012;36 (3):118-123. doi:10.1016/j.farma.2011.02.003

36. Dalageorgou C. The need of information in clinical settings. Heal Res J. 2020;6(2):51. doi:10.12681/healthresj.23313

37. Barcelona City Council. Population, household and homes statistics. Readings population register. 2019. Available from: https://www.bcn. cat/estadistica/angles/dades/barris/tpob/pad/padro/a2019/cp24.htm. Accessed July 14, 2020.

38. Leeuw E. Self-administered questionnaires and standardized interviews. In: Alasuutari P, Bickman L, Brannen J, editors. The SAGE Handbook of Social Research Methods. London: SAGE Publications Ltd; 2008:313-327.
Patient Preference and Adherence

\section{Publish your work in this journal}

Patient Preference and Adherence is an international, peer-reviewed, open access journal that focusing on the growing importance of patient preference and adherence throughout the therapeutic continuum. Patient satisfaction, acceptability, quality of life, compliance, persistence and their role in developing new therapeutic modalities and compounds to optimize clinical outcomes for existing disease states are major areas of interest for the journal. This journal has been accepted for indexing on PubMed Central. The manuscript management system is completely online and includes a very quick and fair peer-review system, which is all easy to use. Visit http:// www.dovepress.com/testimonials.php to read real quotes from published authors. 